\title{
Is there any chance for microsurgical reconstructions in elderly?
}

\author{
D Ribuffo ${ }^{1 *}$, A Milia $^{2}$, N Gallus ${ }^{1}$ \\ From de Senectute: Age and Health Forum \\ Catanzaro, Italy. 5-7 December 2009
}

In Italy there is a increase in the percentage of population aged over 70 with a gradual increase in average life expectancy (Table 1).

Some studies show that septuagenarians have a greater chance of survival than octogenarians postoperatively and a lower incidence of mortality perioperatively [1].

Recent studies show that elderliness is not an independent risk factor for microsurgical complications, but it is related to increased incidence of medical complications, particularly in patients with more 'comorbidities' and with a higher American Society of Anesthesiologists status [2]. The need of considering some important aspects during the preoperative phase is important in evaluation of an elderly to be subjected to a microsurgical operation.

These factors are: prolonged operation time due to microsurgical anastomosys; donor site morbidity; condition of recipient vessels. In order to satisfy these criteria, some therapeutic devices could be advanced such as perioperative prophylactic anticoagulation [3].

The indications for microvascular free-tissue transfers (MFTT) in the elderly are different from those in the young: post car-traumas are treated in lower extremity, risks to which an elderly is less exposed. Moreover they are not common operations because elderly vessels are more affected by vascular diseases; in trunk, elderly

Table 1 Mean of average life expectancy

\begin{tabular}{lll}
\hline Age & Man & Female \\
\hline $70-75$ & 11,8 & 15 \\
$75-80$ & 9,1 & 11,7 \\
$80-85$ & 6,8 & 8,7 \\
$>80$ & 5,1 & 6,3 \\
\hline
\end{tabular}

${ }^{1}$ Cattedra di Chirurgia Plastica e Ricostruttiva, Università degli studi Cagliari, Italy

$$
\text { taly }
$$

rarely requires reconstruction. MFTT made in headneck district are the same in percentage as the ones made on the young: if we have a loss of tissue, reconstruction must be immediate in both. Moreover the recipient vessels are less affected by atherosclerosis than peripheral vessels. The percentage of surgical complications is equal in both.

\section{Conclusions}

The limit in MFTT on an elderly patient is notimposed by the technique used but by the request of the patient and by the status of his vessels. If a patient's medical problem doesn't represent a handicap, MFTT can be safely performed in the elderly by using proper techniques and precautions.

\section{Author details}

'Cattedra di Chirurgia Plastica e Ricostruttiva, Università degli studi Cagliari, Italy. ${ }^{2}$ Dipartimento di Discipline Chirurgiche ed Oncologiche, Sezione Chirurgia Plastica, Università di Palermo, Italy.

Published: 19 May 2010

\section{References}

1. Howard MA, et al: Free Tissue Transfer in the Elderly: Incidenceof Perioperative Complications following Microsurgical Reconstruction of 197 Septuagenarians and Octogenarians. Plastic And Reconstructive Surgery 2005, 116(6):1659-1668.

2. Perrot $P$, et al: La reconstruction par lambeau libre chez lesujet age'. Annales de chirurgie plastique esthétique 2008, 53:420-423.

3. Chen HC, M.D., et al: Guidelines for the optimization of microsurgery in atherosclerotic patients. Microsurgery 2006, 26(5):356-362.

\section{doi:10.1186/1471-2318-10-S1-L14}

Cite this article as: Ribuffo et al:: Is there any chance for microsurgical reconstructions in elderly? BMC Geriatrics 2010 10(Suppl 1):L14. 